\title{
Research of Carbon Emission Mechanism Coupling Model and Empirical Case---A Case Study of Beijing
}

\author{
Jianyu $\operatorname{Jin}^{1}$ \\ Jinjianyu_zz@163.com \\ Lifeng Duan ${ }^{1}$
joe_is_here@yahoo.cn
}

\author{
Xiaoliu Shen ${ }^{1}$ \\ shenxiaoliu@163.com \\ Ting $\mathrm{Cao}^{1}$ \\ ct.undersea@gmail.com
}

\section{(1. School of computer and technology North China Electric Power University, Beijing, China)}

\begin{abstract}
At present, $\mathrm{CO}_{2}$ emissions in China has been ranking second in the world, $75 \%$ of it coming from energy consumption. Effective control of $\mathrm{CO}_{2}$ emission has become an urgent problem, and analysis on the impact of factors affecting $\mathrm{CO}_{2}$ emissions will inevitably become the primary solution to this problem. Kaya model is constructed by the product of multiple influencing factors, which associates the $\mathrm{CO}_{2}$ emission quantity with living standards, economic growth, population size and per capita GDP. This study is based on the coupling of Kaya model and LMDI model which is built to comb Beijing's evolution mechanism of carbon emissions from 2001 and 2010, and respectively builds $\mathrm{CO}_{2}$ emission factor separation model and energy consumption factor separation and superposition model to comb the evolution mechanism of Beijing's $\mathrm{CO}_{2}$ emission in different angle of life and production department from 2001 to 2010. The results show that the living standard, economic growth, population size factors have become the main factors affecting the $\mathrm{CO}_{2}$ emissions, and the effect of energy intensity, industrial structure, energy on $\mathrm{CO}_{2}$ emissions has reached a bottleneck. Meanwhile the results of this study can provide policy recommendations for other provinces and cities to reduce $\mathrm{CO}_{2}$ emissions.
\end{abstract}

Index Terms $-\mathrm{CO}_{2}$ emission, Kaya model, logarithmic mean Division index model, The Coupling Model, energy consumption,

\section{INTRODUCTION}

Nowadays reducing the $\mathrm{CO}_{2}$ emission is the main measures to mitigate climate warming for $\mathrm{CO}_{2}$ is the main factor of global climate warming ${ }^{[1]}$. To make sure the emission reduction being reasonable and effective, we must take the $\mathrm{CO}_{2}$ emission mechanism as the major study direction. $\mathrm{CO}_{2}$ emission mechanism studies the process, feature and trend of $\mathrm{CO}_{2}$ emission as well as effects of various factors on $\mathrm{CO}_{2}$ emission and on its change. emission mechanism study is in-deep study of $\mathrm{CO}_{2}$ emission source and level, is key step of $\mathrm{CO}_{2}$ emission reduction, and directly relate to the set of strategic policies and measures in $\mathrm{CO}_{2}$ emission reduction, while at the same time is of important significance for the development of low-carbon economy ${ }^{[2]}$.

\section{MODEL CONSTRUCTION}

Kaya model, which was put forward by Japan scholar Yoichi Kaya and used as one of the main models in $\mathrm{CO}_{2}$ driving factors analysis, is one of the most widely used model $^{[3]}$. Using the product of multiple factors to construct Kaya model, the influencing factors such as living standard, economic growth, population scale and Per Capita GDP can be associated with $\mathrm{CO}_{2}$ emission.

LMDI (logarithmic mean division index) model satisfies the factors reversible, and is able to eliminate residual term, that overcomes the existence of residual term after decomposition and unsuitable decomposition in residual term and make the model more persuasive and widely used ${ }^{[5]}$.

Given this, this article chose the coupling of Kaya model an LMDI model to combs the mechanism of $\mathrm{CO}_{2}$ emission in Beijing.

A. The factorization model of CO2 emission $\mathrm{CO}_{2}$ emission factorization model:

$$
C=\sum_{i} C_{i}=\sum_{i} E S_{i} F_{i}
$$




$$
\Delta C=\Delta C_{E}+\Delta C_{S}+\Delta C_{F}
$$

where,

$$
\begin{aligned}
& \left\{\begin{array}{l}
\Delta C_{E}=\sum_{i} \alpha \ln \left(E_{i}^{t} / E_{i}^{\mathrm{o}}\right) \\
\Delta C_{S}=\sum_{i} \alpha \ln \left(S_{i}^{t} / S_{i}^{\mathrm{o}}\right) \\
\Delta C_{F}=\sum_{i} \alpha \ln \left(F_{i}^{t} / F_{i}^{\mathrm{o}}\right)
\end{array}\right. \\
& S_{i}=E_{i} / E, F_{i}=C_{i} / D \\
& \alpha=\left(C_{i}^{t}-C_{i}^{0}\right) / \ln \left(C_{i}^{t} / C_{i}^{0}\right)
\end{aligned}
$$

$\Delta C_{F}$ - energy carbon emission intensity effect, $E$ - total

energy consumption, $E_{i}$ - the consumption of energy $i, S_{i}$

-proportion of energy $i$ in total energy, $\Delta C_{S}$ - energy structural effect, $D-\mathrm{GDP}, \quad i=1$ for coal, $i=2$ for oil, $i=3$ for gas, $C_{i}$-the carbon dioxide emissions of energy $i$ consumption, $t$-current time period, 0 - basic period, $\Delta C$ -the change of the carbon dioxide emissions between current time period and basic period, $F_{i}$ - carbon emissions intensity, $\Delta C_{E}$ - energy consumption effect.

\section{B. Energy consumption decomposition model}

The total energy consumption $E$ is divided into production energy consumption $\boldsymbol{E}_{P}$ and life energy consumption $E_{R}$ :

$$
E=E_{P}+E_{R}=\sum_{j} E_{P, j}+E_{R}
$$

$E_{P}$ - production energy consumption, $E_{R}$ - life energy consumption, $E_{p, j}$ - energy consumption of the industrial sector $j$ in production. This build production factors extension model and life extension model, and establish the corresponding relationship with $N 、 Q 、 I 、 M 、 P$.

Energy consumption decomposition extension model in production department:

$$
\begin{aligned}
& E_{P}=\sum_{j} E_{P, j}=\sum_{j} N Q I_{j} M_{j} \\
& \Delta E_{P}=\Delta E_{N 1}+\Delta E_{Q}+\Delta E_{I}+\Delta E_{M}
\end{aligned}
$$

where,

$$
Q=G / N, I_{j}=G_{j} / G, M_{j}=E_{P, j} / G_{j},
$$

$$
\begin{aligned}
& \left\{\begin{array}{l}
\Delta E_{N 1}=\sum_{j} \beta \operatorname{In}\left(N_{i}^{t} / N_{i}^{\mathrm{o}}\right) \\
\Delta E_{Q}=\sum_{j} \beta \operatorname{In}\left(Q_{i}^{t} / Q_{i}^{\mathrm{o}}\right) \\
\Delta E_{I}=\sum_{j} \beta \operatorname{In}\left(I_{i}^{t} / I_{i}^{\mathrm{o}}\right) \\
\Delta E_{M}=\sum_{j} \beta \operatorname{In}\left(M_{i}^{t} / M_{i}^{\mathrm{o}}\right)
\end{array}\right. \\
& \beta=\left(E_{p, j}^{t}-E_{p, j}^{\mathrm{o}}\right) / \operatorname{In}\left(E_{p, j}^{t} / E_{p, j}^{\mathrm{o}}\right)
\end{aligned}
$$

where, $Q$ - Per Capita GDP, using $j=1,2,3$ respectively indicate for industrial sector $j, G$-GDP, $G_{j}$ -production value of industrial sector $j, E_{p, j}$-energy consumption of industrial sector $j, \Delta E_{Q}, \Delta E_{N 1}, \Delta E_{M}, \Delta E_{I}$ respectively indicate economic growth, population scale, energy consumption intensity and industrial structure.

Life factor decomposition extension model:

$$
\left\{\begin{array}{l}
E_{R}=N P \\
\Delta E_{R}=E_{R}^{t}-E_{R}^{0}=\Delta E_{N 2}+\Delta E_{p}
\end{array}\right.
$$

where,

$$
\begin{aligned}
& P=E_{R} / N \\
& \left\{\begin{array}{l}
\Delta E_{N 2}=\gamma \ln \left(N^{t} / N^{0}\right) \\
\Delta E_{P}=\gamma \ln \left(p^{t} / p^{0}\right)
\end{array}\right. \\
& \gamma=\left(E_{R}^{t}-E_{R}^{\mathrm{o}}\right) / \operatorname{In}\left(E_{R}^{t} / E_{R}^{\mathrm{o}}\right)
\end{aligned}
$$

$P$-per capita consumption, $\Delta E_{R}$ - energy consumption during the relative time, $\Delta E_{N 2}$-population size influence factor in life department, $\Delta E_{P}$-living level influence factor.

\section{CO2 emission factor superposition model}

The superposition of production department and life department influence establishes the factor superposition model:

$$
\Delta C=\Delta C_{N}+\Delta C_{Q}+\Delta C_{I}+\Delta C_{M}+\Delta C_{P}+\Delta C_{S}+\Delta C_{F}
$$

where,

$$
\begin{gathered}
\Delta C_{N}=\left[\left(\Delta E_{N 1}+\Delta E_{N 2}\right) / \Delta E\right] / \Delta C_{F} \\
\Delta C_{Q}=\left(\Delta E_{Q} / \Delta E\right) \Delta C_{E}
\end{gathered}
$$




$$
\Delta C_{I}=\left(\Delta E_{I} / \Delta E\right) \Delta C_{E}, \Delta C_{P}=\left(\Delta E_{P} / \Delta E\right) \Delta C_{E}
$$

In the equations, $\triangle C$ is for the current changes in $\mathrm{CO}_{2}$ emissions relative to the base period, $\Delta C_{N}$-population factor, $\Delta C_{Q}$-economic growth factor, $\Delta C_{I}$ - industrial structure factor, $\Delta C_{M}$-energy consumption intensity factor, $\Delta C_{P}$-living level factor.

\section{CARBON EMISSION MECHANISM ANALYSIS}

\section{A. analysis on results of Beijing CO2 emissions model}

Beijing proposed an energy-supplying system, which is both multilevel complemented and accommodated and harmoniously developed. The system is electric-oriented, assisting with oil, gas, coal and renewable sources. During the ten years from 2001 to 2010 , the proportion of coal fells to $73 \%$, the proportion of oil is $9 \%$, and the proportion of natural gas rise to $18 \%$, but coal is still occupies a high proportion among the three. Coal has the highest emission coefficient and the largest proportion among three kinds of energy, followed by oil and gas. In order to reduce the emission of $\mathrm{CO}_{2}$, we must upgrade the industrial structure ${ }^{[6 \sim 7]}$.

From the Fig. 1 we can see that in the first five years, the emission of $\mathrm{CO}_{2}$ in Beijing is in a rapid increase trend. But then it is in a year-by-year decreasing trend from 2005 to 2010. The change of energy consumption and energy structure is positive, that increased the $\mathrm{CO}_{2}$ emission. And with the upgrade of energy structure, contribution rate is also firstly in increasing trend and then in decreasing trend. $\Delta C_{S}$ is negative and restrains $\mathrm{CO}_{2}$ emission, while the contribution rate is also negative, that means the energy structure has little effect on $\mathrm{CO}_{2}$ emissions.

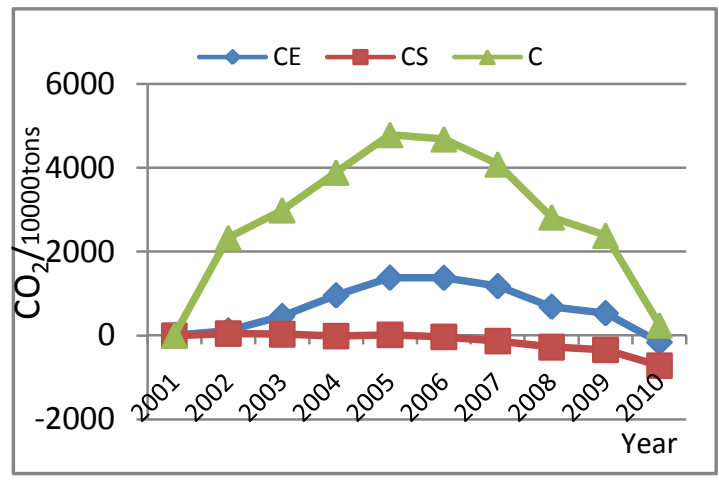

Fig.1. model decomposition results of $\mathrm{CO}_{2}$ emissions in Beijing from 2001 to 2010

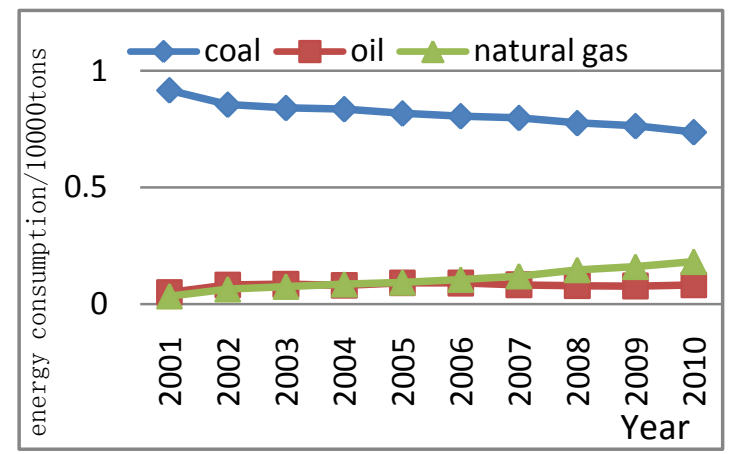

Fig.2. the change trend of Beijing's energy structure during 2001 2010

B. Analysis on the result of energy consumption separation model

According to Fig.3, the total consumption of energy is in increasing trend during the ten years from 2001 to 2010, and the living energy consumption factor has less effect in $\mathrm{CO}_{2}$. $E_{P}$ and $E_{R}$ all increased, but the amplification of $E_{R}$ is relatively small for its lower influence, while the growth rate of $E_{P}$ is in fleetness increasing tendency for its larger influence on $E$, especially before 2007. The growth rate slowed down after 2007 under the influence of the policy on energy white paper which released by the state council in December 2007.

Among the changes of $E$ form 2001 to 2010, the contribution of change $E_{P}$ is about $82 \% \sim 86 \%$, and is $13 \% \sim 17 \%$ for change $E_{R}$. This is related to the respectively proportion of $E_{P}$ and $E_{R}$ in Beijing. From 2001 to 2010, $E_{P}$ keep sharing above $80 \%$ in $\boldsymbol{E}$, though there is decreasing in every years, and the sharing rate of $E_{R}$ is keeping slow increasing.

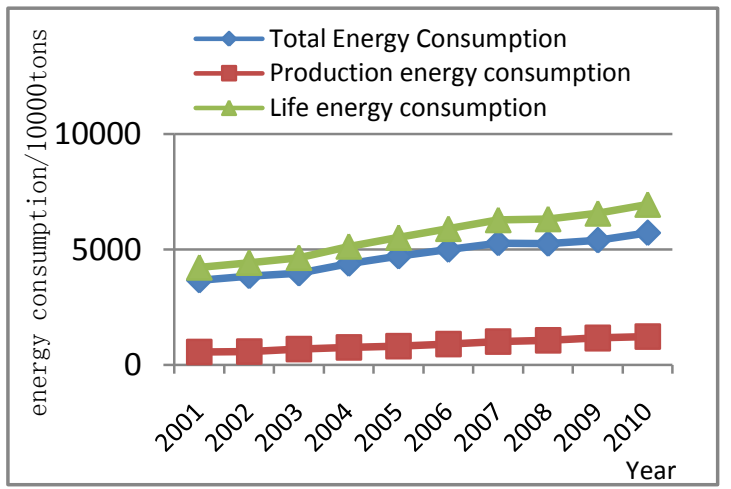

Fig.3. Results of Beijing energy consumption separation model form 2001 to 2010 
TABLE.1. Results of Beijing energy consumption separation model form

\begin{tabular}{|l|c|c|}
\hline \multicolumn{3}{|c|}{2001 to 2010} \\
\hline Year & $\begin{array}{l}\text { Consumption contribution } \\
\text { of production }\end{array}$ & $\begin{array}{c}\text { Consumption } \\
\text { contribution of life }\end{array}$ \\
2001 & 0.867343 & 0.132657 \\
2003 & 0.868355 & 0.131645 \\
2004 & 0.853572 & 0.146428 \\
2005 & 0.853736 & 0.146264 \\
2006 & 0.852519 & 0.147481 \\
2007 & 0.845966 & 0.154034 \\
2008 & 0.840053 & 0.159947 \\
2009 & 0.831009 & 0.168991 \\
2010 & 0.822412 & 0.177588 \\
\hline
\end{tabular}

In Fig.4, we can find that among the numerous factors, the per capita energy consumption factor occupies a large proportion in the production department, and the proportion of other factors is relatively smaller. And $M$ take a negative effect on $\mathrm{CO}_{2}$ emission while other factors take a positive effect.

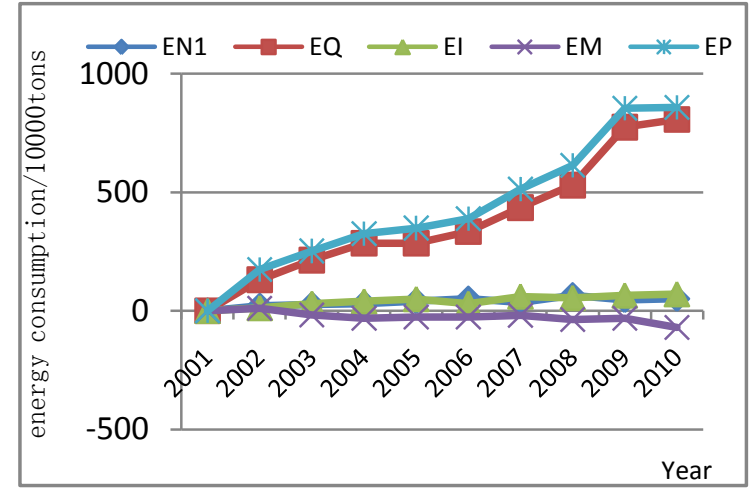

Fig.4. Accumulation of consumption separation model's results from 2001 to 2010

Fig.5 is the Beijing energy intensity change trend chart. From this chart we can see that the energy intensity of first industry and third industry all in decreasing tendency, but in a low rate, and decline in second industry is larger than the other two industries, so changes in industry structure make the $E_{P}$ reduced. During the ten years from 2001 to2010 present in Fig.6, the output ratio of the first and second industry is in decreasing tendency, while the third industry's output ratio is in increasing tendency. Fig. 5 presents the changing trend of Beijing's energy intensity in each industry from 2001 to 2010. We can see that the influence degree of industry structure and
$\mathrm{CDP}$ on $\mathrm{CO}_{2}$ emission is decreasing year by year, especially ine policies during this ten years. So, during the period of 2001 2010, the industry structure changes make $E_{P}$ reduced. From the Fig.4, we can find that the population scale in living department continued increasing since 2001. Beijing is the political and economic center of our country and Beijing's pouring into employment makes the living energy consumption increasing, that turn out to be the increasing of $\mathrm{CO}_{2}$ emission.

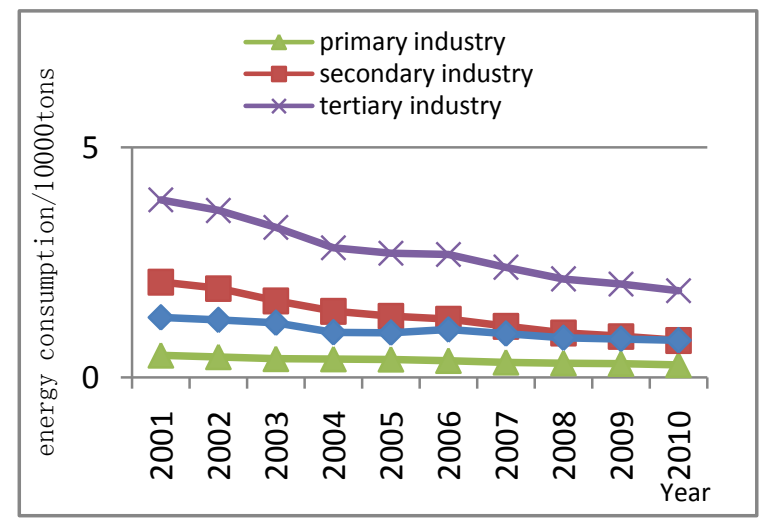

Fig.5. Changing trend of Beijing's energy intensity in each industry from 2001 to 2010

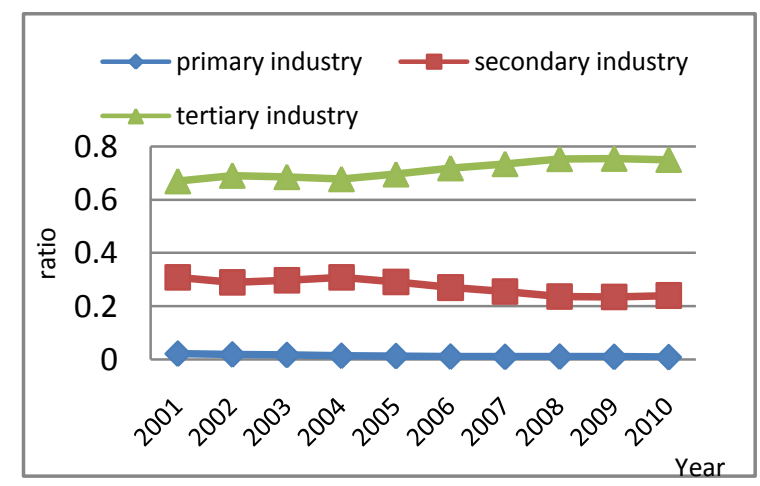

Fig.6. the proportion change tendency of industrial structure of Beijing form 2001 to 2010

Form Fig.7 we can see that the population scale factor in production department occupies a steady contribution to energy consumption which is in positive increasing trend. And the influence degree is gradually increased with the rapid growth of contribute rate after 2008. Changes in living level have made a great influence in energy consumption, and have led the total energy consumption to in a significant growth trend. Though the contribution of it in 2005 and 2010 has some ups-and-downs, it still occupies a relatively larger proportion on the whole. 


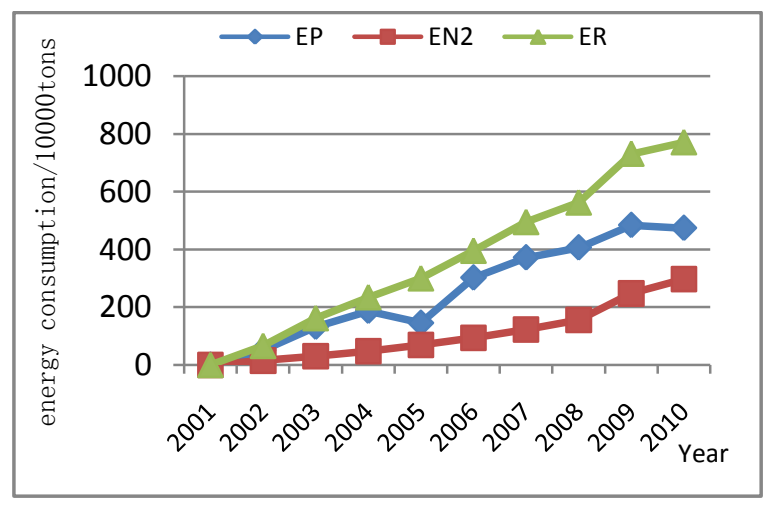

Fig.7. Accumulation of life energy consumption model decomposition from 2001 2010

Table 2 shows the contribution rate of each $\mathrm{CO}_{2}$ emissions factor. What can be seen from the above conclusions is that from 2001 to 2010 there are two adjustable factors affect the $\mathrm{CO}_{2}$ emission decline in Beijing. They are adjustment of economic growth and per capita energy consumption. Decline in energy intensity can also partly be the reason of the reduction in $\mathrm{CO}_{2}$ emissions. The contribution rate of it gradually increased from $28.41 \%$ in 2001 to $88.20 \%$ in 2010. Due to the conflict between Q and $\mathrm{CO}_{2}$ emission reduction, it is needed to take the per capita energy consumption, industry structure and other factors into consideration for ensuring economic growth while reducing $\mathrm{CO}_{2}$ emissions. From 2001 to 2010, energy intensity in
Beijing play an inhibitory effect on $\mathrm{CO}_{2}$ emissions. In 2010 the contribution rate of it is about $-7.7 \%$. Contribution rate of Beijing's industrial structure is positive. The contribution rate gradually increased from $2.61 \%$ in 2001 to $7.76 \%$ in 2010 , because the impact factor is relatively small, the adjustment of industrial structure has been basically saturated. From 2001 to 2010, what the energy intensity decline restrains in the $\mathrm{CO}_{2}$ emissions has reached bottleneck, therefore we need to reduce $\mathrm{CO}_{2}$ emissions from other factors adjustment. The contribution rate of population scale is maintained in the range of $7.74 \%$ to $38.08 \%$ in the production and living consumption. Population growth will inevitably lead to big margin increasing in energy consumption, so population control became one of the main factors for controlling $\mathrm{CO}_{2}$ emissions. The optimization of $\mathrm{S}$ has reduced $\mathrm{CO}_{2}$ emissions, but the contribution rate is low because of the obvious change on $\mathrm{S}$. Although the contribution rate of $\mathrm{S}$ has ups and downs, it is in a decreasing tendency on the whole which restrains $\mathrm{CO}_{2}$ emissions. This is mainly associated with Beijing's coal-dominated energy endowment and the further development of new energy and renewable energy policy initiatives. Optimization of $\mathrm{S}$ will help a lot in reducing $\mathrm{CO}_{2}$ emission.

TABLE 2. The contribution of various factors on $\mathrm{CO} 2$ emissions

$\%$

\begin{tabular}{|l|l|l|l|l|l|l|}
\hline Year & $\Delta C_{Q} / \Delta C$ & $\Delta C_{I} / \Delta C$ & $\Delta C_{M} / \Delta C$ & $\Delta C_{P} / \Delta C$ & $\Delta C_{S} / \Delta C$ & $\Delta C_{N} / \Delta C$ \\
\hline 2002 & 28.40905 & 2.60896 & 2.360913 & 37.83144 & 21.04507 & 7.744566 \\
2003 & 37.80993 & 5.391104 & -3.09846 & 44.64412 & 5.346109 & 9.907207 \\
2004 & 41.33855 & 5.801082 & -4.52014 & 47.07683 & -1.05704 & 11.36071 \\
2005 & 36.7675 & 6.477096 & -3.44273 & 45.07501 & 0.854089 & 14.26904 \\
2006 & 39.30852 & 3.55886 & -3.13045 & 45.68385 & -2.3597 & 16.93893 \\
2007 & 42.08083 & 5.900807 & -1.80878 & 49.65998 & -11.2157 & 15.38289 \\
2008 & 58.40464 & 6.060367 & -4.06211 & 67.59418 & -52.4072 & 24.41013 \\
2009 & 82.92724 & 7.00418 & -3.28576 & 91.54925 & -109.619 & 31.42432 \\
2010 & 88.20065 & 7.7596 & -7.6654 & 93.86104 & -77.97604 & 38.08366 \\
\hline
\end{tabular}

\section{IN CONCLUSION}

1) It can be obtained by the above conclusions after analyzing each $\mathrm{CO}_{2}$ emission affected factors, that the contribution rate of energy intensity, which is an important factor, is in decreasing tendency and restrains the $\mathrm{CO}_{2}$ emission. However, the contribution rate of economic growth presents an upward trend in every year 
and the effect of it grows positively. This is affected by present policy of Beijing, it indicate the impact of Beijing's industry structure upgrade on $\mathrm{CO}_{2}$ emissions has reached bottleneck. What led to the increase of life energy consumption is the increase in population scale and the improvement of living standards. During the decade from 2001 to 2010, contribution rate of living standard has increased from $37.83 \%$ to $93.86 \%$, and the contribution rate of population scale in a decade rose from $7.74 \%$ to $38.08 \%$. On the whole, main influence factors on $\mathrm{CO}_{2}$ emissions in Beijing are ranked as living standards, economic growth and population scale at present. What the energy intensity and industry structure impact on $\mathrm{CO}_{2}$ emissions has reached a saturation state. Its means Beijing has made great efforts in industry structure upgrading and reached the effect of energy saving and emission reduction. Thus advisory policy recommendations can be formed to be used for other provinces' and cities' industry structure upgrade.

2) Controlling the per capita consumption and the population size has become the current suggested measures of control $\mathrm{CO}_{2}$ emissions in Beijing in order to guarantee of economic growth at the same time. In the long term, it's awful necessary to take developing new energy and renewable energy instead of coal consumption as a strategic policy to reduce emissions.

\section{ACKNOWLEDGMENT}

This work was financially supported by: (1) Beijing
Natural Science Foundation (9122021). (2) Beijing City Government in Support of Universities in Beijing to Build the Projects (Project Name: Research of Beijing energy industry comprehensive risk management system model and decision support platform).(3) Beijing City Government in Support of Universities in Beijing to Build the Projects(Project Name: The Study of Resource-Economy-Environment Sustainable

Development System Planning and Decision Support in Beijing-Tianjin-Hebei Area).

\section{REFERENCES}

[1] Zheng Xin, Yang Jing, Wang Lisheng. China's $\mathrm{CO}_{2}$ emissions prediction from the burning of fossil fuels [J]. Water Resources and Power, 2009,27(5): 224-227.

[2] Xu Guoquan, Liu Zeyuan, Jiang Zhaohua, China's carbon emissions factor decomposition model and empirical analysis: 1995-2004 [J]. China Population Resources and Environment,2006,16(6):158-161.

[3] Stephen D. Casler, Adam Rose. Carbon Dioxide Emissions in the U.S. Economy: A Structural Decomposition Analysis[J]. Environ-mental and Resource Economics, 1998, 11(3-4): 349-363.

[4] Chung HS, Rhee H C. A Residual- free Decomposition of the Sources of Carbon Dioxide Emissions: A Case of the Korean Indus-tries [J].ENERGY, 2001, 26(1): 15-30.

[5] J W Testeret a.1 Sustainable Energy: Choosing among Options [M].US: MIT Press, 2005. 